\title{
Out-of-pocket Expenditure in Childhood Cancer during the COVID-19 pandemic in an LMIC
}

ESSY MARADIEGUE ${ }^{1}$, Ivan Maza ${ }^{2}$, Sharon Chavez ${ }^{1}$, Lourdes Aranda ${ }^{3}$, Claudia Pascual ${ }^{4}$, Henry Garcia ${ }^{5}$, Rodolfo Paredes ${ }^{6}$, Carolina Riojas $^{7}$, Annaly Benavente ${ }^{1}$, Miguel Gonzales ${ }^{8}$, Isabel Hurtado ${ }^{3}$, Betsy Cabrera ${ }^{5}$, Christopher Machado ${ }^{6}$, Erick Mattos ${ }^{3}$, Victor Palacios ${ }^{9}$, Mariela Tello ${ }^{10}$, and Liliana Vasquez ${ }^{4}$

${ }^{1}$ Instituto Nacional de Enfermedades Neoplasicas

${ }^{2}$ Hospital Nacional Edgardo Rebagliati Martins

${ }^{3}$ National Hospital Edgardo Rebagliati Martins

${ }^{4}$ Pan American Health Organization

${ }^{5}$ Instituto Regional de Enfermedades Neoplasicas del Sur

${ }^{6}$ Hospital Belen De Trujillo

${ }^{7}$ Hospital Regional de Lambayeque

${ }^{8}$ Presidencia del Consejo de Ministros

${ }^{9}$ Estado Peruano Ministerio de Salud

${ }^{10}$ Rebagliati Hospital

July 27, 2021

\begin{abstract}
The COVID-19 pandemic has led to unprecedented economic and health vulnerability and inequities globally. This study aims to determine the out-of-pocket (OOP) expenditure of families of children with cancer in Peru before and during the COVID-19 pandemic. We conducted a cross-sectional survey of 235 parents and caregivers of children diagnosed with cancer in Peru. Our study suggests that OOP expenses in these families constitute a catastrophic expense for health. This situation was aggravated due to a decrease in the economic income for most families due to the disruption in formal and informal employment.
\end{abstract}

\section{Hosted file}

Out of pocket 08 de julio.docx available at https://authorea.com/users/330956/articles/ 531925-out-of-pocket-expenditure-in-childhood-cancer-during-the-covid-19-pandemic-in-an$\operatorname{lmic}$ 


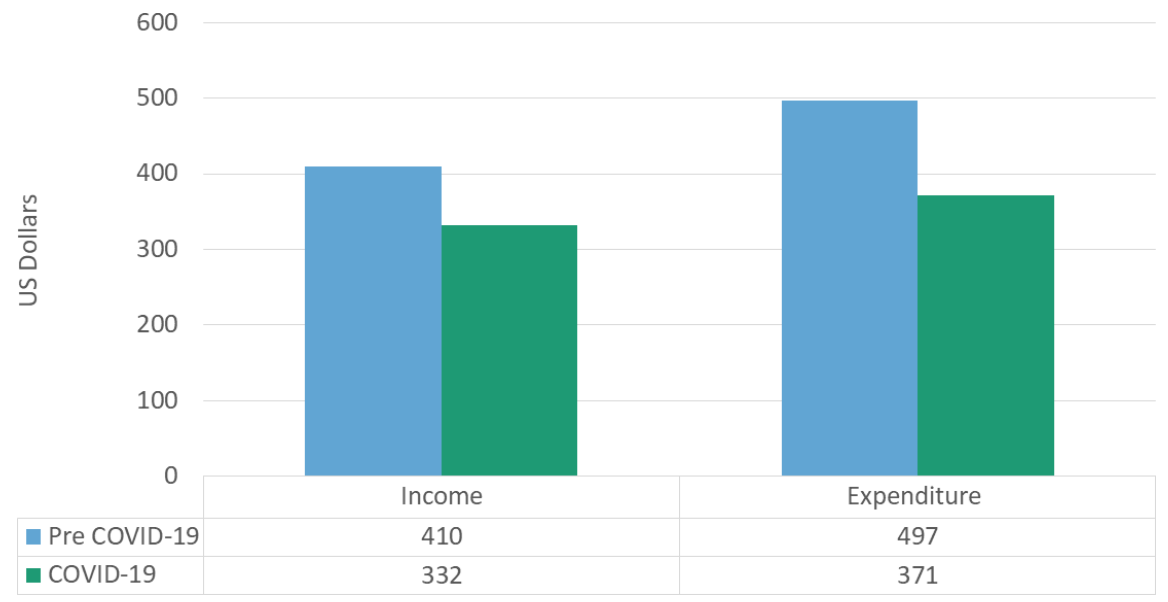

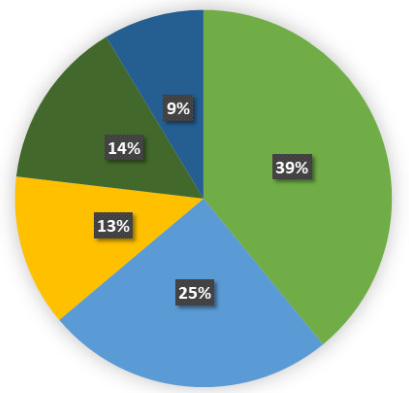

Before the cancer diagnosis
— Diagnostic tests

- Drugs

- Transportation

- Food

- Lodging

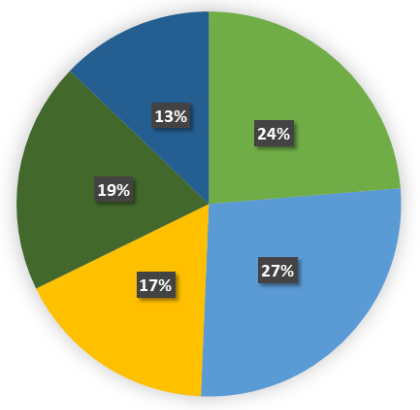

After the cancer diagnosis 